\title{
Relationship between Cognitive Function and Employment in Japanese Schizophrenia Patients
}

\author{
Tomoya Takeda1, Masahito Tomotake ${ }^{2}$, Yoshinori Ueoka ${ }^{3}$, Tsunehiko Tanaka ${ }^{4}$, \\ Takeo Tominaga ${ }^{1}$, Yasuhiro Kaneda ${ }^{5}$, Tetsuro Ohmori ${ }^{1}$ \\ ${ }^{1}$ Department of Psychiatry, Institute of Biomedical Sciences, Tokushima University Graduate School, \\ Tokushima, Japan \\ ${ }^{2}$ Departments of Mental Health, Institute of Biomedical Sciences, Tokushima University Graduate School, \\ Tokushima, Japan \\ ${ }^{3}$ Department of Clinical Psychology, Institute of Socio-Arts and Sciences, Tokushima University Graduate School, \\ Tokushima, Japan \\ ${ }^{4}$ Department of Community Psychiatric Medicine, Shiga University of Medical Science, Ōtsu, Japan \\ ${ }^{5}$ Department of Psychiatry, Iwaki Clinic, Iwaki, Japan \\ Email: tomotake@tokushima-u.ac.jp
}

Received 13 October 2015; accepted 11 January 2016; published 14 January 2016

Copyright (C) 2016 by authors and Scientific Research Publishing Inc.

This work is licensed under the Creative Commons Attribution International License (CC BY). http://creativecommons.org/licenses/by/4.0/

c. (i) Open Access

\begin{abstract}
The purpose of the present study was to examine the relationship between cognitive function and employment in Japanese schizophrenia patients. Subjects were 61 outpatients. Cognitive function was assessed using the Brief Assessment of Cognition in Schizophrenia. Clinical symptoms were also evaluated with the Positive and Negative Syndrome Scale and the Calgary Depression Scale for Schizophrenia. Verbal memory $(F(1,58)=5.50, p=0.02)$ and attention and speed of information processing scores $(F(1,58)=4.92, p=0.03)$ showed significant differences between employment and unemployment groups. Logistic regression analysis showed that employment was significantly predicted by verbal memory $\left(x^{2}=16.09, \mathrm{df}=2, \mathrm{p}=0.01\right)$ and depression scores $\left(\mathrm{x}^{2}=16.09, \mathrm{df}=\right.$ $2, p=0.02$ ). The results suggest that improving verbal memory and depression may lead to employment in Japanese schizophrenia patients.
\end{abstract}

\section{Keywords}

Cognitive Function, Employment, Schizophrenia, Verbal Memory 


\section{Introduction}

Social and occupational impairment has long been recognized to be a core feature of schizophrenia. Previous research groups have studied the relationship between cognitive and occupational functions in schizophrenia patients [1]-[5], and it has been reported that cognitive function is an important determinant of social function and employment [5] [6]. Among several domains of cognitive function, verbal memory and executive function appear to be mainly associated with better social function [5] [6], and improvement in verbal memory was found to be a better predictor of employment outcome than other cognitive function [1]. MuGurk et al. (2000) reported that cognitive function in working memory, verbal memory and vigilance was significantly different between employment and no employment groups. But, MuGurk et al. (2000) showed that positive and negative symptoms were not different between employment and no employment groups. On the other hand, several recent studies have showed that positive and negative symptoms might be more important than cognitive function with regard to functional outcome and employment [7] [8]. As for Japanese patients, previous research reported that cognitive function of Japanese schizophrenia patients showed a score of one to two orders below that of healthy controls in several cognitive dimensions, particularly verbal memory, working memory, motor speed, verbal fluency, attention and speed of information processing, and executive function [9]. There has been evidence of relationships between cognitive function and clinical symptom [10] or quality of life [11]. However, there is no report exploring the relationship between cognitive function and employment in Japanese schizophrenia patients. The purpose of the present study was to investigate the relationship between cognitive function and employment in Japanese schizophrenia patients. We analyzed our previous data in terms of employment.

\section{Methods}

\subsection{Subjects}

Clinical data were collected at Department of Psychiatry, Tokushima University Hospital from 1 October 2007 to 31 March 2009. Treating psychiatrists consecutively asked 77 stabilized outpatients with a DSM-IV diagnosis of schizophrenia. Subjects were excluded if they presented with any organic central nervous system disorder, epilepsy, mental retardation, severe somatic disorder, drug dependence, or alcohol dependence. Of 77 patients, 62 gave us written informed consent to participate in this study. As one subject did not complete all the assessments, data from 61 were used for analysis. Our sample consisted of 33 were men and 28 women. Their mean age was 40.1 years $(\mathrm{SD}=12.2)$. They had been receiving regular outpatient treatment and had not been hospitalized in the previous 6 months. 45 subjects had followed the same antipsychotic regimen for at least 6 months before recruitment. Although 16 had slight changes in their regimen, they were judged as clinically stabilized by the treating psychiatrists. In the present study, the subjects were divided into employment (full time or part time job) and unemployment groups according to their job status data obtained when cognitive function tests were carried out.

\subsection{Procedure}

To assess cognitive function, we used the Brief Assessment of Cognition in Schizophrenia (BACS). The domains of cognitive function that are evaluated by the BACS are verbal memory (list learning), working memory (digit sequencing task), motor speed (token motor task), verbal fluency (category instances and controlled oral word association test), attention and speed of information processing (symbol coding), and executive function (tower of London). It was reported that the Japanese version of it was a reliable and practical scale to evaluate cognitive function in schizophrenia patients [12]. In the present study, the BACS data were collected by clinical psychologists who were very experienced and well trained for the use of it. Clinical symptoms were evaluated with the Positive and Negative Syndrome Scale (PANSS) and the Calgary Depression Scale for Schizophrenia (CDSS). The score of the PANSS ranges from 30 to 210 for the global score, and higher score indicates a greater level symptoms severity. Interviews were conducted by experienced psychiatrists according to the evaluation Manual for the PANSS [13] [14]. The CDSS was specifically developed to distinguish depressive symptoms from positive and negative symptoms or antipsychotic-induced adverse effects. This scale is a 9-item questionnaire (depression, hopelessness, self-deprecation, guilty ideas of reference, pathological guilt, morning depression, early awakening, suicidality, and observed depression), and higher score indicates a greater levels of depression. The reliability and validity of the scale have been verified [15] [16]. In addition, drug induced extra- 
pyramidal symptoms were assessed with the Drug Induced Extra-Pyramidal Symptoms Scale (DIEPSS). It is composed of eight individual parameters (gait, bradykinesia, sialorrhea, muscle rigidity, tremor, akathisia, dystonia, and dyskinesia) and one global assessment. Higher score indicates greater level of extrapyramidal adverse effects. In this study, the sum of eight individual parameters was considered the extrapyramidal symptoms score. Interviews were conducted by experienced psychiatrists according to the Rater's Manual for the DIEPSS [17].

\subsection{Statistical Analysis}

Data analysis was conducted using the PASW Statistics 18 software (SPSS Japan institute 2009). The comparison of demographic indices between employment and unemployment groups was carried out using unpaired t-test or Mann-Whitney U test. Next, using the analysis of covariance test (ANCOVA) including the variables that showed significant differences in the preceding comparison as a covariate, cognitive function between the two groups was compared. Finally, a logistic regression analysis was performed to explore which of clinical variables that showed significant differences in the comparison would be independent variables for employment.

\subsection{Ethical Considerations and Conflict of Interest}

This study was approved by the Ethics Committee of Tokushima University Hospital. The authors declare that they have no conflicts of interest. All authors certify their responsibility for the manuscript.

\section{Results}

The differences in cognitive function as well as clinical indices between employment and unemployment groups were shown in Table 1 . The BACS score was standardized by creating z-scores whereby the healthy control

Table 1. Demographic characteristics of subjects (mean \pm SD).

\begin{tabular}{|c|c|c|c|c|}
\hline & & Employment & Unemployment & P value \\
\hline N (men/women) & & $17(4 / 13)$ & $44(29 / 15)$ & \\
\hline Age (years) & & $39.50 \pm 13.75$ & $40.38 \pm 11.65$ & \\
\hline Education (years) & & $13.88 \pm 2.01$ & $13.23 \pm 2.04$ & \\
\hline Duration of illness (years) & & $13.93 \pm 7.94$ & $16.11 \pm 9.73$ & \\
\hline Number of hospitalizations & & $1.71 \pm 1.65$ & $2.32 \pm 2.55$ & \\
\hline $\begin{array}{l}\text { Dose of antipsychotics } \\
\text { (mg/day })^{\dagger}\end{array}$ & & $516.00 \pm 615.34$ & $691.09 \pm 448.92$ & $\mathrm{P}=0.04^{2)}$ \\
\hline $\begin{array}{l}\text { Dose of anti-Parkinson drug } \\
(\mathrm{mg} / \text { day })^{\ddagger}\end{array}$ & & $2.41 \pm 2.80$ & $2.24 \pm 2.29$ & \\
\hline \multirow{2}{*}{ PANSS } & Positive syndrome & $10.94 \pm 3.77$ & $14.23 \pm 4.86$ & $\mathrm{P}=0.01^{2)}$ \\
\hline & Negative syndrome & $15.00 \pm 5.77$ & $19.23 \pm 6.64$ & $\mathrm{P}=0.03^{1)}$ \\
\hline CDSS & & $1.53 \pm 1.88$ & $3.80 \pm 3.30$ & $\mathrm{P}=0.01^{2)}$ \\
\hline DIEPSS & & $0.76 \pm 1.20$ & $1.93 \pm 2.62$ & \\
\hline \multirow{6}{*}{ BACS (Z-score) } & Verbal memory & $-0.92 \pm 1.24$ & $-1.98 \pm 1.18$ & $\mathrm{P}<0.01^{1)}$ \\
\hline & Working memory & $-0.79 \pm 1.16$ & $-1.40 \pm 1.95$ & $\mathrm{P}=0.05^{2)}$ \\
\hline & Motor speed & $-1.21 \pm 1.57$ & $-2.05 \pm 1.62$ & \\
\hline & $\begin{array}{l}\text { Attention and speed of } \\
\text { information processing }\end{array}$ & $-0.95 \pm 1.12$ & $-1.93 \pm 1.12$ & $\mathrm{P}<0.01^{1)}$ \\
\hline & Verbal fluency & $-0.49 \pm 1.06$ & $-0.95 \pm 1.12$ & \\
\hline & Executive function & $-0.78 \pm 1.34$ & $-1.36 \pm 2.13$ & \\
\hline
\end{tabular}

${ }^{\dagger}$ Chlorpromazine equivalent, ${ }^{\ddagger}$ Biperiden equivalent. PANSS, Positive and Negative Syndrome; CDSS, Calgary Depression Scale for Schizophrenia; DIEPSS, Drug Induced Extra-Pyramidal Symptoms Scales; BACS, Brief Assessment of Cognition in Schizophrenia. ${ }^{1)}$ Unpaired t-test, ${ }^{2)}$ Mann-Whitney U test. 
mean was set to zero and the standard deviation set to one. The control data were collected from our study [12]. The mean age of the healthy control subjects $(n=76)$ was 38.3 years $(S D=14.2)$. Z-scores of employment group $(\mathrm{N}=17)$ and unemployment group $(\mathrm{N}=44)$ were calculated based on the mean scores of healthy control subject. Z-scores of employment group were $-0.92(\mathrm{SD}=1.24)$ for verbal memory, $-0.79(\mathrm{SD}=1.16)$ for working memory, $-1.21(\mathrm{SD}=1.57)$ for motor speed, $-0.95(\mathrm{SD}=1.12)$ for attention and speed of information processing, $-0.49(\mathrm{SD}=1.06)$ for verbal fluency, and $-0.78(\mathrm{SD}=1.34)$ for executive function. Z-scores of unemployment group were $-1.98(\mathrm{SD}=1.18)$ for verbal memory, $-1.40(\mathrm{SD}=1.95)$ for working memory, -2.05 $(\mathrm{SD}=1.62)$ for motor speed, $-1.93(\mathrm{SD}=1.12)$ for attention and speed of information processing, $-0.95(\mathrm{SD}=$ 1.12 ) for verbal fluency, and -1.36 ( $S D=2.13$ ) for executive function. As for the comparison between the employment and unemployment groups, there were significant differences in verbal memory $(\mathrm{t}(59)=-3.09, \mathrm{p}<$ $0.01)$, working memory $(\mathrm{U}=191.50, \mathrm{p}=0.05)$, and attention and speed of information processing $(\mathrm{t}(59)=-3.08$, $\mathrm{p}<0.01)$ between the two groups. Dose of antipsychotics $(\mathrm{U}=243.50, \mathrm{p}=0.04)$, positive syndrome $(\mathrm{U}=$ 216.00, $\mathrm{p}=0.01)$ and negative syndrome $(\mathrm{t}(59)=2.31, \mathrm{p}=0.03)$ scores of the PANSS, and the CDSS score $(\mathrm{U}=$ 215.50, $\mathrm{p}=0.01$ ) showed significant differences between the two groups. ANCOVA as taking dose of antipsychotics, scores of positive and negative syndromes of the PANSS, the CDSS score as a covariate showed significant differences in verbal memory $(F(1,58)=5.50, \mathrm{p}=0.02)$ and attention and speed of information processing scores $(F(1,58)=4.92, p=0.03)$ between the two groups. Logistic regression analysis showed that employment was significantly predicted by the BACS verbal memory score $\left(\mathrm{x}^{2}=16.09, \mathrm{df}=2, \mathrm{p}=0.01\right)$ and the CDSS score $\left(x^{2}=16.09, \mathrm{df}=2, \mathrm{p}=0.02\right)$.

\section{Discussion}

The results of this study indicated that there were significant differences in cognitive function, and clinical symptoms between employment and unemployment groups. The differences in cognitive function between the two groups have been reported previously. McGurk et al. (2000) reported that there were significant differences in working memory, verbal memory and vigilance between the two groups. However, the study did not show any difference in positive and negative symptoms. On the other hand, several studies demonstrated that psychopathology might be more important than cognitive function with regard to functional outcomes [7] [8] [18]. In the present study, we found that both cognitive function and clinical symptoms are related to employment. Among the BACS domains, verbal memory and attention and speed of information processing remained significant even after statistically eliminating the effect of other clinical factors. Our results are consistent with Kaneda et al.'s report (2010) indicating that neurocognitive performance in verbal working memory and attention might be important to improve employment outcome. The results of logistic regression analysis showed that employment could be significantly predicted by the verbal memory function and depressive level in Japanese schizophrenia patients. Verbal memory has been reported to be important cognitive domain that affects social function [5] [6] [19] [20]. In addition, depressive symptoms have been found to affect schizophrenia patient's quality of life and life skills [21]-[23]. The present results also suggest that depressive symptom is an important variable for employment. Since some treatment modalities such as cognitive behavior therapy and cognitive remediation therapy have been found to be effective for depression and cognitive impairment of schizophrenia patients [24] [25], it is suggested that treatment efforts should focus on improving verbal memory and depression in order to achieve better employment. The current study has some limitations. The sample size was relatively small. In addition, the subjects showed relatively mild symptoms. Therefore, there is a possibility that our results do not reflect the characteristics of the whole schizophrenia patients.

\section{Conclusion}

The present study showed that employment was significantly predicted by verbal memory and depression. The results suggest that improving verbal memory and depression may lead to employment in Japanese schizophrenia patients.

\section{Acknowledgements}

The authors would like to thank all patients for participating in this study. 


\section{References}

[1] Kaneda, Y., Jayathilak, K. and Meltzer, H. (2010) Determinants of Work Outcome in Neuroleptic-Resistant Schizophrenia and Schizoaffective Disorder: Cognitive Impairment and Clozapine Treatment. Psychiatry Research, 178, 57-62. http://dx.doi.org/10.1016/j.psychres.2009.04.001

[2] McGurk, S.R. and Mueser, K.T. (2004) Cognitive Functioning, Symptoms, and Work in Supported Employment: A Review and Heuristic Model. Schizophrenia Research, 70, 147-173. http://dx.doi.org/10.1016/j.schres.2004.01.009

[3] Bryson, G. and Bell, M. (2003) Initial and Final Work Performance in Schizophrenia: Cognitive and Symptom Predictors. The Journal of Nervous and Mental Disease, 191, 87-92. http://dx.doi.org/10.1097/01.NMD.0000050937.06332.3C

[4] Martinez-Aran, A., Penades, R., Vieta, E., Colom, F., Reinares, M., Benabarre, A., et al. (2002) Executive Function in Patients with Remitted Bipolar Disorder and Schizophrenia and Its Relationship with Functional Outcome. Psychotherapy and Psychosomatic, 71, 39-46. http://dx.doi.org/10.1159/000049342

[5] Green, M.F., Kern, R.S., Braff, D.L. and Mintz, J. (2000) Neurocognitive Deficits and Functional Outcome in Schizophrenia: Are We Measuring the "Right Stuff”? Schizophrenia Bulletin, 26, 119-136. http://dx.doi.org/10.1093/oxfordjournals.schbul.a033430

[6] McGurk, S.R. and Meltzer, H.Y. (2000) The Role of Cognition in Vocational Functioning in Schizophrenia. Schizophrenia Research, 45, 175-184. http://dx.doi.org/10.1016/S0920-9964(99)00198-X

[7] Ertugrul, A. and Ulug, B. (2002) The Influence of Neurocognitive Deficits and Symptoms on Disability in Schizophrenia. Acta Psychiatrica Scandinavica, 105, 196-201. http://dx.doi.org/10.1034/j.1600-0447.2002.1020.x

[8] Norman, R.M., Malla, A.K., Cortese, L., Cheng, S., Diaz, K., Mclntosh, E., et al. (1999) Symptoms and Cognition as Predictors of Community Functioning: A Prospective Analysis. American Journal of Psychiatry, 156, 400-405.

[9] Kaneda, Y., Sumiyoshi, T., Nakagome, K., Numata, S., Tanaka, T., Ueoka, Y., et al. (2008) The Brief Assessment of Cognition in Schizophrenia Japanese Version (BACS-J). SeishinIgaku, 50, 913-917. (In Japanese)

[10] Tanaka, T., Tomotake, M., Ueoka, Y., Kaneda, Y., Taniguchi, K., Nakataki, M., et al. (2012) Clinical Correlates Associated with Cognitive Dysfunction in People with Schizophrenia. Psychiatry and Clinical Neurosciences, 66, 491-498. http://dx.doi.org/10.1111/j.1440-1819.2012.02390.x

[11] Ueoka, Y., Tomotake, M., Tanaka, T., Kaneda, Y., Taniguchi, K., Nakataki, M., et al. (2011) Quality of Life and Cognitive Dysfunction in People with Schizophrenia. Progress in Neuro-Psychopharmacology and Biological Psychiatry, 35, 53-59. http://dx.doi.org/10.1016/j.pnpbp.2010.08.018

[12] Kaneda, Y., Sumiyoshi, T., Keefe, R.S., Ishimoto, Y., Numata, S. and Ohmori, T. (2007) Brief Assessment of Cognition in Schizophrenia: Validation of the Japanese Version. Psychiatry and Clinical Neurosciences, 61, 602-609. http://dx.doi.org/10.1111/j.1440-1819.2007.01725.x

[13] Kay, S.R., Fiszbein, A. and Opler, L.A. (1987) The Positive and Negative Syndrome Scale (PANSS) for Schizophrenia. Schizophrenia Bulletin, 13, 261-276. http://dx.doi.org/10.1093/schbul/13.2.261

[14] Kay, S.R., Opler, L.A. and Fiszbein, A. (1991) Positive and Negative Syndrome Scale (PANSS) Rating Manual. Seiwa, Tokyo.

[15] Addington, D., Addington, J. and Maticka-Tyndale, E. (1993) Assessing Depression in Schizophrenia: The Calgary Depression Scale. British Journal of Psychiatry, 163, 39-44.

[16] Kaneda, Y., Fujii, A. and Ohmori, T. (2000) Psychometric Properties of the Japanese Version of the Calgary Depression Scale for the Schizophrenics. Journal of Nervous and Mental Disease, 188, 237-239. http://dx.doi.org/10.1097/00005053-200004000-00008

[17] Inada, T. (1996) Evaluation and Diagnosis of Drug-Induced Extrapyramidal Symptoms: Commentary on the DIEPSS and Guide to Its Usage. Seiwa, Tokyo.

[18] Mohamed, S., Rosenheck, R., Swartz, M., Stroup, S., Lieberman, J.A. and Keefe, R.S. (2008) Relationship of Cognition and Psychopathology to Functional Impairment in Schizophrenia. American Journal of Psychiatry, 165, 978-987. http://dx.doi.org/10.1176/appi.ajp.2008.07111713

[19] Bryson, G., Bell, M., Kaplan, E. and Greig, T. (1998) The Functional Consequences of Memory Impairments on Initial Work Performance in People with Schizophrenia. The Journal of Nervous and Mental Disease, 186, 610-615. http://dx.doi.org/10.1097/00005053-199810000-00004

[20] Jager, J. and Douglas, E. (1992) Neuropsychiatric Rehabilitation for Persistence Mental Illness. Psychiatric Quarterly, 63, 71-94. http://dx.doi.org/10.1007/BF01064683

[21] Aki, H., Tomotake, M., Kaneda, Y., Iga, J., Kinouchi, S., Shibuya-Tayoshi, S., et al. (2008) Subjective and Objective Quality of Life, Levels of Life Skills, and Their Clinical Determinants in Outpatients with Schizophrenia. Psychiatry Research, 158, 19-25. http://dx.doi.org/10.1016/j.psychres.2006.05.017 
[22] Yamauchi, K., Aki, H., Tomotake, M., Iga, J.-I., Numata, S., Motoki, I., et al. (2008) Predictors of Subjective and Objective Quality of Life in Outpatients with Schizophrenia. Psychiatry and Clinical Neuroscience, 62, 404-411. http://dx.doi.org/10.1111/j.1440-1819.2008.01818.x

[23] Tomotake, M., Kaneda, Y., Iga, J., Kinouchi, S., Tayoshi, S., Motoki, I. and Sumitani, S. (2006) Subjective and Objective Measures of Quality of Life Have Different Predictors for People with Schizophrenia. Psychological Reports, 99, 477-487. http://dx.doi.org/10.2466/pr0.99.6.477-487

[24] Wykes, T. and Reeder, C. (2005) Cognitive Remediation Therapy for Schizophrenia: Theory and Practice. BrunnerRoutledge, London.

[25] Inoue, K. and Kawabata, S. (1999) Cognitive Therapy for a Major Depressive Episode in Residual Schizophrenia. Psychiatry and Clinical Neuroscience, 53, 563-567. http://dx.doi.org/10.1046/j.1440-1819.1999.00606.x 